Table. Causes of facial dystonia

\begin{tabular}{|c|c|}
\hline Neurodegenerative causes & Secondary \\
\hline Progressive supranuclear palsy & $\begin{array}{l}\text { Drug induced (e.g. } \\
\text { Neuroleptics, levodopa) }\end{array}$ \\
\hline Multiple system atrophy & $\begin{array}{l}\text { Peripherally-induced } \\
\text { (e.g. after local trauma) }\end{array}$ \\
\hline Corticobasal degeneration & $\begin{array}{l}\text { Vascular (e.g. thalamic } \\
\text { hemorrhage) }\end{array}$ \\
\hline Wilson disease & $\begin{array}{l}\text { Paraneoplastic (e.g. } \\
\text { anti-Ri, anti-NMDA) }\end{array}$ \\
\hline Neuroacanthocytosis & $\begin{array}{l}\text { Autoimmune (e.g. } \\
\text { Sjoegren syndrome, APL) }\end{array}$ \\
\hline Neuroferritinopathy & $\begin{array}{l}\text { Psychogenic (e.g. fixed } \\
\text { dystonia of the lower lip) }\end{array}$ \\
\hline
\end{tabular}

PKAN

Lesch-Nyhan disease

mg (normal range 78-280), confirming the diagnosis of GM1 Gangliosidosis.

Type 3 GM1 gangliosidosis is characterized by onset around the second decade of life with slowly progressive extrapiramidal signs, such as dystonia and parkinsonism ${ }^{1}$. There is also a high prevalence of gait disturbance and dysarthria. Other symptoms are short stature, bone abnormalities, cognitive impairment, ataxia and cardiac disorders ${ }^{3}$. Orofacial dystonia is a common feature of type 3 GM1 gangliosidosis, with a prevalence of $87.5 \%$ according to a recent report ${ }^{2}$.

Facial dystonia with proeminent involvement of oromandibular muscles is a frequent manifestation of neuroleptic induced movement disorders ${ }^{4,5}$. However, there is also a number of dystonia syndromes in wich proeminet orofacial involvement occur, and their presence should alert the clinician to their possibility (Table).

We suggest that in patients with early-onset dystonia, the occurance of facial grimacing should lead to

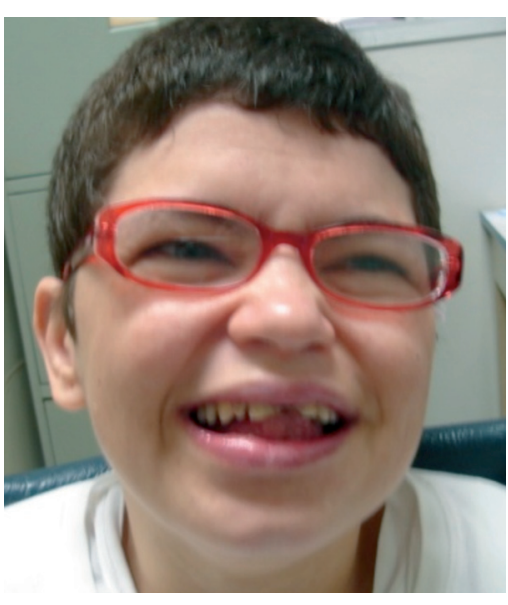

Figure. Facial grimacing and tongue dystonia.

the consideration of type 3 GM1 gangliosidosis, particularly when associated with speech and cognitive impairment, gait disturbances and bone abnormalities.

\section{REFERENCES}

1. Roze E, Paschke E, Lopez N, et al. Dystonia and parkinsonism in GM1 Type 3 gangliosidosis. Mov Disord 2005;20:1366-1369.

2. Muthane U, Chickabasaviah Y, Kaneski C, et al. Clinical features of adult GM1 gangliosidosis: report of three Indian patients and review of 40 cases. Mov Disord 2004;19:1334-1341.

3. Brunetti-Pierri N, Scaglia F. GM1 gangliosidosis: Review of clinical, molecular, and therapeutic aspects. Mol Genet Metab 2008;94:391-396.

4. Tan E-K, Jankovic J.Tardive and idiopathic oromandibular dystonia: a clinical comparison J Neurol Neurosurg Psychiatry 2000;68:186-190.

5. Balasubramaniam R, Saravanan R. Orofacial movement disorders. Oral Maxillofac Surg Clin North Am 2008;20:273-285

FACIAL GRIMACING COMO PISTA PARA O DIAGNÓSTICO DE GANGLIOSIDOSE GM1 TIPO 3

Ambulatório de Neurologia Geral, Departamento de Neurologia e Neurocirurgia, Universidade Federal de São Paulo, São Paulo SP, Brazil.

Correspondence: Ricardo Oliveira Horta Maciel - Rua Tenente Gomes Ribeiro 30/123 - 04038-040 São Paulo SP - Brasil. E-mail: ric.ohmaciel@gmail.com

Received 1 February 2011. Accepted 8 February 2011.

\title{
Huntington's disease presenting as posterior cortical atrophy
}

\author{
Leonardo Caixeta
}

Neuroimaging and neuropathological studies on Huntington's disease (HD) have historically focused on striatal atrophy ${ }^{1}$. In posterior cortical atrophy (PCA), there is a progressive impairment of high-level visual functions and parietal damage ${ }^{2}$. The conundrum of PCA is that while the clinical presentation is relatively homogeneous, the nosological status remains something of a puzzle. We report a case of HD presenting as PCA. 


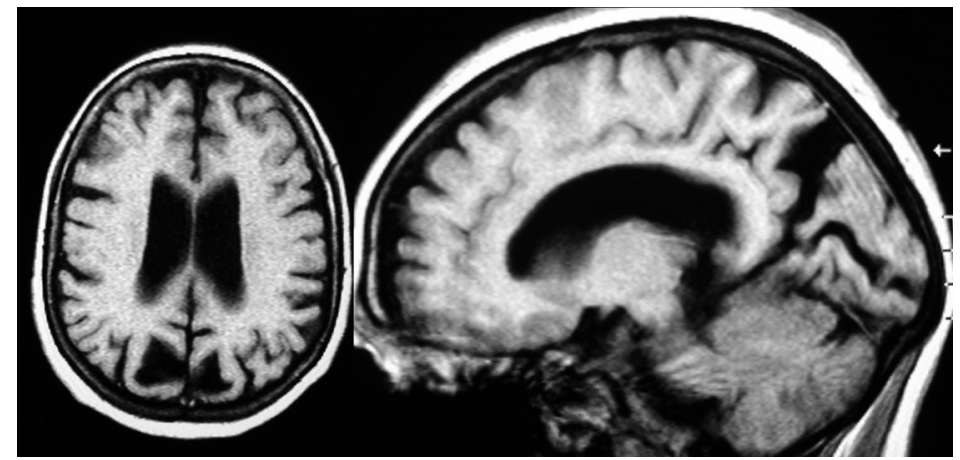

Figure. MRI (axial and sagittal slices weighted in T1) showing focal bilateral occipital and parieto-occipital atrophy, respectively.
A 67-year-old right-handed retired seamstress presented to the Memory Clinic with a history that began 11 years ago when she presented with depressive symptoms featured by tearfulness, sadness, insomnia, loss of weight. One year after, she began with difficulties putting line on the needle and grasping objects (she stopped cutting clothes to sew), i.e. she had difficulty in performing manual tasks under visual guidance bilaterally (optic ataxia). Besides that, she presented jerky intrusions when attempting to perform smooth pursuit eye movements (ocular apraxia) and could not notice two objects at the same time (simultanagnosia).

Two years later, she began with chorea on her upper and lower limbs and face that worst gradually.

The visual processing deficits were interpreted in the beginning as part of Alzheimer's disease. Until six years ago, most of her activities of daily living were spared. Two years ago became demented, totally dependent upon caregivers and restricted to wheelchair because of gait instability and falls.

She has no familiar antecedents of Huntington's disease, notwithstanding both her parents deceased when they were young (father: 33 year-old; mother: 28 years-old).

Present neurological exam revealed important chorea in head and limbs, severe dysartria, dystonia in both hands, brisk symmetric tendon reflexes with left Babinski sign, Balint syndrome. On cognitive examination, she scored 8 out of 30 points on the MMSE.

Patient has genetically confirmed CAG repeats in the abnormal range ( 1 allele with 41 repeats and other with 18). The MRI showed focal cortical bilateral atrophy in occipital and parieto-occipital lobes (Figure), as well as bicaudate atrophy.

The primary site of pathology in HD is the caudate nucleus, however cortical changes are also commonly reported ${ }^{1,3,4}$. While many researchers have studied pathology in the frontal lobe, little attention has been paid to posterior cortical regions. Recent neuroimaging studies have documented prominent progressive cortical thinning in parietal and occipital cortices, even in the years preceding motor onset ${ }^{3,4}$. Some HD patients may preferentially target posterior cortical regions, particularly the angular gyrus which has a significant projection to the caudate nucleus in primates ${ }^{3}$. Visuomotor integration deficits may be evident many years before the clinical onset of $\mathrm{HD}^{5}$.

We describe a functional impact of posterior cortical pathology on the clinical phenotype of HD, in an early phase of the disease, in line with imaging data of posterior atrophy. The clinical phenotype of HD is far more complex and variable than depictions of it as a progressive movement disorder dominated by neostriatal pathology represent. This is the first HD case report presenting as a PCA phenotype in the early premotor phase of HD. Therefore, HD should be remembered as a possible etiology when considering PCA syndrome.

\section{REFERENCES}

1. Rosas HD, Liu AK, Hersch SM. Regional and progressive thinning of the cortical ribbon in Huntington's disease. Neurology 2002;58:695-701.

2. Areza-Fegyveres R, Caramelli P, Porto CS, et al. The syndrome of progressive posterior cortical dysfunction: a multiple case study and review. Dement Neuropsychol 2007;1:311-319.

3. Macdonald V, Halliday GM, Trent RJ, McCusker EA. Significant loss of pyramidal neurons in the angular gyrus of patients with Huntington's disease. Neuropathol Appl Neurobiol 1997;23:492-495.

4. Rosas HD, Salat DH, Lee SY, et al. Cerebral cortex and the clinical expression of Huntington's disease: complexity and heterogeneity. Brain 2008; 131:1057-1068.

5. Say MJ, Jones R, Scahill RI, et al. Visuomotor integration deficits precede clinical onset in Huntington's disease. Neuropsychologia. 2011;49:264-270.

\section{DOENÇA DE HUNTINGTON SE APRESENTANDO COMO ATROFIA CORTICAL POSTERIOR}

Professor Associado de Neuropsiquiatria do Curso de Medicina da Universidade Federal de Goiás (UFG). Coordenador do Ambulatório de Neuro-Demências do Hospital das Clínicas da UFG. Programas de Pós-Graduação em Saúde Pública do Instituto de Patologia Tropical e Saúde Pública e Programa de Ciências da Saúde da Faculdade de Medicina da UFG, Goiânia Go, Brazil.

Correspondence: Leonardo Caixeta - Instituto da Memória e do Comportamento - Avenida Cristo Rei 62 - 74674-290 Goiânia GO - Brasil. E-mail: leonardocaixeta1@gmail.com

Received 19 January 2011. Received in final form 4 February 2011. Accepted 11 February 2011. 